\title{
Pluralismo das abordagens em Economia como uma realidade: a Comissão Econômica para América Latina e Caribe ${ }^{1}$
}

\author{
Pluralism of approaches in Economics as a reality: \\ the ECLAC (Economic Comission for LatinAmerica and the Caribbean)
}

\author{
Maisa Goulart \\ maisagsr@gmail.com \\ Universidade Federal do ABC (UFABC) \\ Ramón García Fernández \\ ramon.fernandez@ufabc.edu.br \\ Universidade Federal do ABC (UFABC)
}

\begin{abstract}
Resumo: Este trabalho analisa, por meio de revisão bibliográfica, as propostas e desdobramentos do estruturalismo histórico desenvolvido pela Comissão Econômica para América Latina e Caribe (CEPAL) como um exemplo da aplicação do pluralismo das abordagens em economia. Entende-se o estruturalismo cepalino como uma teoria econômica voltada à análise da realidade latino-americana que recupera argumentos provenientes das teorias pós-keynesiana, institucionalista, clássica, marxista e inclusive da neoclássica. Para desenvolver a argumentação, após uma introdução, as posições tradicionais bem como as mais recentes sobre o pluralismo das abordagens em economia são revistas na segunda seção. A terceira seção apresenta o histórico e algumas propostas cepalinas que incorporam argumentos provenientes das teorias antes mencionadas, com a finalidade de exemplificar as possibilidades do pluralismo das abordagens em um caso prático e aplicado, como explicitamos na conclusão.
\end{abstract}

Palavras-Chave: História do Pensamento Econômico; Pluralismo; CEPAL

Código JEL: B2.

Abstract: This paper analyzes, through a bibliographic review, the proposals and developments of historical
structuralism developed by the Economic Commission for Latin America and the Caribbean (ECLAC) as an
example of the application of the pluralism of approaches in economics. ECLAC structuralism is understood as
an economic theory focused on the analysis of Latin American reality that reclaims arguments from post-
Keynesian, institutionalist, Marxian, classical and even of neoclassical theories. To achieve this goal, after a
short introduction, traditional as well as recent discussions on the pluralism of approaches in Economics are
presented in the second section. The third section presents the history and some ECLAC proposals that
incorporate arguments from the aforementioned theories, with the purpose of verifying the possibilities of a
pluralist approach in a practical and applied case, as we explained in the conclusion.

Keywords: History of Economic Thoughts; Pluralism; ECLAC

JEL Code: B2.

Recebido em: 28-02-2018. Aceito em: 25-06-2018.

\footnotetext{
1Os autores agradecem os comentários à primeira versão do artigo feitos por Armando Di Filippo (CEPAL); agradecem também os efetuados por dois pareceristas anônimos desta revista. Uma versão anterior deste artigo foi apresentada no XII Congresso Brasileiro de História Econômica em Niterói, em 2017.
} 


\section{INTRODUÇÃO}

Pensar a ciência econômica como uma física social, em termos de 'hard Science', é uma atitude recorrentemente contestada por muitos pesquisadores da área, especialmente no período posterior à crise de 2008, que alterou o cenário socioeconômico a nível mundial; isso provocou o questionamento ainda com maior vigor da atividade dos economistas. A discussão, no entanto, não é tão nova quanto pode parecer a primeira vista: a insatisfação com a adoção de um tipo de pensamento econômico homogeneizado e determinado a priori, ou seja, com a adoção do mainstream econômico ${ }^{2}$ de forma acrítica, já vinha sendo explicitada há muito tempo. Entre outras respostas nesse sentido, encontra-se o pensamento cepalino, que foi desenvolvido como alternativa nos anos 1950, por meio de suas análises históricoestruturalistas.

A criação da Comissão Econômica para América Latina e Caribe - de agora em diante apenas CEPAL - e a formação desse novo olhar, voltado para a América Latina, condensa o esforço de analisar uma realidade particular lançando mão de elementos de teorias econômicas distintas (por exemplo: pós-keynesiana, institucionalista, schumpeteriana e marxista). Uma teoria própria foi assim formulada, sem o intuito de ser uma generalização teoricamente aplicável a toda e qualquer realidade, senão com o objetivo de iluminar problemas singulares dentro do território latino-americano, considerando sua formação histórica e os desafios, que associados ao seu desenvolvimento específico. Como afirma Di Filippo (2007):

La noción de desarrollo utilizada por los miembros de la ELD ${ }^{3}$ experimentó, durante ese largo período una transformación desde visiones eminentemente económicas hacia otras crecientemente interdisciplinarias. Este ensayo sugiere que la ELD fue capaz de reformular crítica y constructivamente las principales categorías analíticas de las ciencias sociales del mundo académico occidental, para lograr una interpretación propia, históricamente fundada de las realidades sociales latinoamericanas. (p. 141).

\footnotetext{
${ }^{2}$ Os termos mainstream, ortodoxo e neoclássico são usados neste trabalho em forma intercambiável, como referência à posição teórica dominante em economia. Estamos cientes de que esses termos podem ter implicações diferentes, conforme desenvolvido por Colander (2000) e Dequech (2007), entre outros, mas para os objetivos deste trabalho a sinonímia é aceitável, especialmente porque a crítica do pluralismo se dirige ao conjunto da perspectiva que é denominada por esses três termos por diferentes pessoas em diversas circunstâncias.

${ }^{3}$ Armando Di Filippo denomina esta perspectiva como Escuela Latinoamericana del Desarrollo (ELD), acrescentando que: "Esta es la denominación con la que este ensayo engloba las contribuciones de distinguidos científicos sociales que durante cincuenta años (1950-2000) articularon sus ideas en torno a la visión centro periferia formulada originalmente por la CEPAL en su ampliamente conocido Estudio Económico de América Latina - 1949”. (DI FILIPPO, 2007, p.140)
} 
Em termos práticos, a criação da CEPAL implicou também na aproximação entre pessoas que advogam por mais espaço para correntes marginalizadas, compreendendo as deficiências da ortodoxia, mas também os limites das teorias heterodoxas.

Dessa forma, a coexistência de múltiplas teorias foi proposta como uma alternativa para permitir o aumento do conhecimento em economia e, consequentemente, para poder enfrentar com maior eficiência os problemas socioeconômicos da região. A proposta da CEPAL, em termos gerais, pode ser considerada como uma tentativa de reconectar teoria e realidade, por meio da crítica ao mainstream, visto não apenas como uma proposta para construir uma ciência econômica mais plural, mas também pela recuperação de uma visão da economia que defende um caráter social e que dialoga com outras ciências da mesma área, tais como história, sociologia e ciência política, argumento que serve em favor da interdisciplinaridade (CASANOVA, 2006).

Nesse espírito, Axel Leijonhfvud (1973) escreveu o artigo "Life Among The Econ ${ }^{4}$, , texto metafórico que descreve os economistas como uma tribo (os Econs) que mora numa região desolada e inóspita; seriam eles pessoas que não aceitariam o relacionamento com as outras tribos (ou seja, as outras ciências sociais), tornando-os completamente isolados e de difícil diálogo com os vizinhos, apesar da origem comum; isso permite ao autor dizer:

Embora as tribos tenham uma origem comum, são delicadas as relações entre elas. A desconfiança e o desdém com que o Econ mediano encara seus vizinhos é ardorosamente retribuído por eles que também não morrem de amores pelos Econ. As relações sociais entre as tribos acham-se bloqueadas por numerosos tabus. O extremado espírito de clã (para não dizer xenofobia) dos Econ torna dura a vida em sua tribo - e a torna um tanto perigosa para os estrangeiros. (LEIJONHFVUD, 1973, p.169-170)

Nesse sentido, o objetivo deste trabalho é apresentar o contexto da constituição da teoria histórico-estruturalista, proposta pela CEPAL, bem como os principais atores que participaram em sua criação e as múltiplas influências recebidas na formulação

\footnotetext{
${ }^{4}$ Life among the Econ (1973) é um texto já clássico em economia, cuja ironia sobressai por meio de uma crítica à desconexão da economia com as ciências sociais, consideradas 'tribos de origem comum'. $\mathrm{O}$ texto também apresenta críticas à convivência, na própria "tribo dos Econs", de suas "castas" (macro, micro, econometria e desenvolvimento), mostrando o quanto é difícil o relacionamento entre os próprios economistas. $\mathrm{O}$ artigo, por fim, também assume uma postura crítica e contrária à aceitação da teoria neoclássica como mainstream em economia, questionando a utilização excessiva de técnicas matemáticas e o dogmatismo inerente a essa atitude, que exclui ou marginaliza as outras correntes teóricas.
} 
dessa teoria, mostrando-a como uma aplicação prática do pluralismo das abordagens em economia. Assim, a segunda seção apresenta a discussão acerca das possiblidades de adoção do pluralismo em economia, através de uma revisão bibliográfica. A terceira seção, por sua vez, será dividida em dois blocos: o primeiro sobre o processo de formação da CEPAL como centro de pensamento econômico latino-americano, cujos autores principais têm/tiveram relevância ímpar para a tomada de decisões políticoeconômicas; o segundo apresentará os elementos incorporados à teoria históricoestruturalista provenientes de outras correntes teóricas. Por fim, as considerações finais evidenciam a relação entre o conceito de pluralismo e a proposta cepalina.

\title{
O PLURALISMO DAS ABORDAGENS EM ECONOMIA
}

A tarefa de conceituar o pluralismo das abordagens em economia é complexa, mas em linhas gerais, diz respeito à aceitação de que os fatos econômicos, por sua complexidade e interligação com fatores históricos, políticos, sociais, institucionais e ideológicos (e isso para não falar em questões comportamentais/psicológicas ou mesmo culturais e antropológicas dos agentes econômicos) podem ser tratados sob diferentes perspectivas analíticas, ganhando assim em variedade e profundidade de compreensão (FERNANDEZ, 2011).

O pluralismo parte de entender que há uma inconsistência lógica na aceitação de alguma teoria como representativa da verdade, crítica relacionada ao falibilismo:

\begin{abstract}
En la epistemología contemporánea el pluralismo es una consecuencia inevitable en casi todas las corrientes de pensamiento. Este concepto supone otro previo, el de falibilismo. Basicamente nos vemos obligados a aceptar el pluralismo de teorías y de métodos a partir de la constatación que la verdad no se obtiene o no se puede probar acerca de los enunciados más interesantes de los cuales constan las teorías, las leyes científicas. (SCARANO, 2005, p.2)
\end{abstract}

O conceito de falibilismo foi popularizado por Popper (1934), embora também tenha sido muito trabalhado anteriormente por Peirce $(1935)^{5}$. Neste sentido, Marin

\footnotetext{
5 Embora a questão do falibilismo não seja tema central desta pesquisa, é importante mencionar a pesquisa de Charles Sanders Pierce sobre a questão do falibilismo. Haack (2002) sugere que "há uma espantosa semelhança entre Popper e Pierce, principalmente se considerarmos que Popper desconhecia quase que completamente o trabalho de Pierce. A noção de ciência dos autores apresenta muitas similaridades, sobretudo na ênfase à sua falibilidade, que se contrapõe à crença tradicional de ciência como conhecimento universal e necessário". Todavia, Santos (2006), em sua tese doutoral dedicada a encontrar e discorrer sobre os pontos de inflexão e semelhanças entre as duas teorias, explicita que a
} 
(2008) pontua que "por falibilismo se entende que não existe certeza do conhecimento ou verdade, pois todo conhecimento é conjectural e, por abordagem crítica, ele [Popper] quer demonstrar o que justamente foi denominado de racionalismo crítico.” (p.82). Com isso, a associação do falibilismo com o ideal pluralista extrapola a questão puramente lógica, acentuando a necessidade de debate e diálogo para o desenvolvimento científico, como expõem Schorn e Falkenbach (2010):

O falibilismo é um processo dedutivo de verificação, chave metodológica para a abertura do conhecimento e da produção científica à crítica; com ele, a objetividade científica está firmada na disposição a exercer e aceitar crítica e, por esse caminho, perseguir a verdade. Essa forma de racionalidade distingue ciência e não-ciência pela atitude crítica no aprendizado com a experiência. (SCHORN e FALKENBACH, 2010, p. 39)

O problema lógico que envolve o falibilismo tem relação com a impossibilidade de se supor que uma relação entre eventos seja contínua e válida, em ocasiões variadas e em situações futuras. No entanto, não defende o abandono da racionalidade devido à impossibilidade de 'ter certeza'; muito pelo contrário, a postura defendida por Popper valoriza o debate e o diálogo crítico como forma de não abandonar a racionalidade, considerada inerente ao processo de desenvolvimento científico.

A discussão sobre a possibilidade de compreender o pluralismo como uma abordagem adequada para o ensino e a pesquisa em economia iniciou-se a muito tempo e, mesmo que em alguns momentos tenha sido deixada de lado, sempre formou parte das preocupações dos economistas. Uma manifestação pioneira do espírito pluralista aparece na obra de John Neville Keynes (1891), precursor desta perspectiva, em um contexto em que havia uma disputa na ciência econômica, conhecida como batalha dos métodos ${ }^{6}$, entre a tradição clássica inglesa, como reformulada pela escola austríaca, e a

falibilidade da ciência, para Popper "deve-se a nossa impossibilidade de estabelecer a verdade de uma teoria por verificação. Assim, trabalha-se com hipóteses que podem ser falsas e busca-se o seu falseamento." Ou seja, cada vez que um erro é descoberto, aproxima-se da verdade que é, deveras, inatingível. Em contrapartida, para Pierce "Se por um lado, deve-se à nossa impossibilidade de esgotar o conteúdo significativo de um signo, cujo interprete final é sempre projetado para adiante por outro, devese ao próprio caráter de indeterminação do objeto (acaso). Num mundo em que a generalidade cresce e se complexifica, nunca poderemos abarcar o seu todo" (SANTOS, 2006, p. 112). Neste tópico, os autores agradecem os comentários do professor Manuel Ramon Souza Luz (UFABC), que estimularam esta reflexão.

${ }^{6}$ De origem alemã, Methodenstreit, traduz-se como batalha dos métodos. Como esclarecimento acerca da teoria por trás da batalha dos métodos, Bianchi (1992, p. 136) afirma: "de um lado, coloca a economia clássica inglesa, na tradição de Smith-Ricardo-Mill-Senior-Cairnes-Bagehot, que encontraria em 1890, nos Principles de Marshall, um tratado antológico. O método preconizado pelos ingleses definia-se como positivo, abstrato e dedutivo, ou seja, a construção teórica assentava-se em princípios a priori. (...) De outro lado, colocava-se a escola histórica alemã, crítica e contestatória em relação ao domínio inglês, a 
escola histórica alemã. Foi nesse contexto que Keynes iniciou a reflexão sobre a suposta necessidade de eleger uma única posição, concluindo que, ao contrário, as duas poderiam coexistir, somando-se:

Se a pura indução é inadequada, a pura dedução é igualmente inadequada. O erro de colocar esses métodos em oposição mútua, como se o emprego de qualquer um deles excluísse o emprego do outro, é infelizmente muito comum. (KEYNES, 1891, p. 172).

A partir das propostas de Neville Keynes quanto ao pluralismo, outros autores como Bruce Caldwell (1982) e Sheila Dow (2004) trabalharam em cima do conceito, em especial para que a crítica, muito comum, acerca da falta de critério das atitudes pluralistas pudesse ser refutada. Em linhas gerais, a preposição de Caldwell teve importância ímpar para o desenvolvimento e aceitação do pluralismo, como esclarecem Goulart, Vasconcelos e Fernandez (2016):

\begin{abstract}
A proposta preliminar - proto-pluralismo - antecedeu uma refinação realizada por Caldwell (1982), em sua publicação "Beyond Positivism: Economic Methodology in the Twentieth Century", sugerindo o que é conhecido como "pluralismo crítico", proposição que recupera as ideias do racionalismo crítico preconizado por Popper, com o objetivo de esquivar-se da eventual anarquia que poderia ser decorrente do pluralismo, antes dito como metodológico. (p.17)
\end{abstract}

Assim, entendemos que Caldwell (1982) elencou pontos para evitar uma desorientação acerca dos critérios para implementar o pluralismo. Também se preocupou com a necessidade imprescindível de dar espaço ao "novo" dentro da Economia, o desejo de que possam existir críticas livres de dogmas. Conforme a sugestão de Bianchi (1992, p.140), sua proposta visava "diminuir a incomensurabilidade entre teorias e promover o diálogo entre diferentes programas de pesquisa."

Caldwell (1982) acredita, em defesa do pluralismo crítico, que a coexistência de teorias e métodos diferentes é benéfica para o desenvolvimento da ciência. Em consonância, a possibilidade de que existam críticas não dogmáticas, e uma defesa ativa delas, é condição sine qua non para a proliferação de novas teorias. Bianchi (1992, p.140) observou que "ele privilegia a crítica interna como a mais efetiva, preferindo-a à crítica externa. A primeira é considerada cabível e oportuna em todos os momentos da ciência, posto que o dogmatismo é uma atitude anticientífica por excelência". Desse modo, o diálogo entre economistas de programas de pesquisa científica distintos seria incentivado de forma que isso traria grande contribuição ao desenvolvimento da ciência.

que N. Keynes se refere às vezes como "escola nova". Seus adeptos propunham um método fortemente assentado no raciocínio indutivo, bastante influenciado pela história e com enfoque interdisciplinar". 


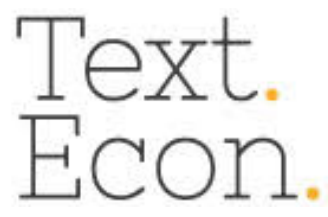

Sheila Dow (2004) também se debruçou sobre a temática, oferecendo uma vasta produção a respeito. Ela manifesta sua preocupação com a impossibilidade lógica de se atingir a verdade por meio de uma única teoria científica. Em seus pesquisas e reflexões sobre teoria macroeconômica, ela busca englobar e reconstruir argumentos das mais diversas escolas do pensamento econômico, compreendendo que podem ser enfoques complementares. A autora assume, como postura ética, o respeito às diversas teorias, mesmo que pareçam incomensuráveis; claro que certamente o faz em tom mais próximo da teoria keynesiana e de crítica ao mainstream ${ }^{7}$.

Em linhas gerais, é importante reiterar que a prática do pluralismo parece muito relacionada a um compromisso ético por parte dos economistas e à reformulação do modo de pensar da comunidade científica em prol de um posicionamento mais aberto (e portanto menos dogmático), com ampla possibilidade de desenvolvimento de novas teorias e defendendo a existência e/ou criação de diferentes programas de pesquisa. É importante considerar que, dada a complexidade da realidade econômica, cada teoria tipicamente é capaz de lançar luz sobre apenas sobre uma parcela dela, mas ao mesmo tempo deve tentar tratá-la em sua totalidade (BIANCHI, 1992). Permitir aos estudantes de graduação em economia, um ensino amplo e constituído por abordagens variadas poderia o primeiro passo para que o pluralismo seja uma realidade.

Deve-se destacar que o pluralismo não é a mesma coisa que o anarquismo metodológico proposto por Paul Feyerabend (1977), nem reflete uma postura do tipo meramente relativista. $\mathrm{O}$ que se propõe é uma atitude, ou uma postura ética, mais aberta e crítica, fazendo disso um hábito enriquecedor, promovendo o diálogo e os critérios racionais (FERNANDEZ, 2011).

Após termos recuperado o conceito de pluralismo, tanto como postura ética como quanto abordagem teórico-metodológica, desenvolveremos nossa intepretação do ideal pluralista que para nós constitui o pano de fundo da formação da CEPAL.

\footnotetext{
${ }^{7}$ A maneira específica na qual Sheila Dow defende o pluralismo foi criticada por Eduardo Scarano. que considera que de alguma maneira a posição dela paradoxalmente acaba sendo pouco pluralista: "Desde nuestro punto de vista hay dos argumentos principales. El primero, su pluralismo solo es compatible con una manera filosófica de entender la realidad, como sistemas abiertos. Deja afuera, por lo tanto, la mayoría de las teorías científicas que han existido hasta este momento. Parece un pluralismo demasiado estrecho y ligado a una filosofía específica. El segundo argumento contra su manera de entender el pluralismo es el excesivo papel que desempeña la filosofía a la que adhiere. Los metodólogos han terminado por aceptar el papel de la filosofía en la generación y desarrollo de teorías científicas. Pero la filosofía siempre está acotada y diferenciada de la ciencia porque esta última es contrastable, se aceptan sus enunciados porque se cotejan con la realidad. En cambio, en Dow este aspecto se debilita hasta casi desaparecer. La economía termina semejándose más a la filosofía que a la manera usual de entender una disciplina científica" (Scarano, 2005, p.12).
} 
Entendemos que a CEPAL viabilizou debates marginalizados pela ortodoxia, promovendo a proliferação de teorias novas, em coexistência. A ideia geral consiste na compreensão de que não há necessidade de que uma teoria ou método seja entendido como o único correto em detrimento dos outros; dessa forma que haverá espaço para todos, cada qual lançando o seu feixe de luz na realidade. Nesse ponto que o estudo da CEPAL ganha destaque, a partir de sua atitude institucional, que levou ao surgimento de uma teoria nova com características muito particulares:

El rasgo más distintivo del estructuralismo fue el abordaje epistemológico con que esas fuentes teóricas de referencia fueron tratadas, dando lugar a la única visión (hasta ese momento) de Economía Política Global no construida por pensadores académicos asociados a los centros hegemónicos del orden mundial. (AHUMADA e DI FILIPPO, p.36)

Entendemos que, desde sua formação, a CEPAL representou um exemplo do aproveitamento do potencial fornecido para a compreensão de uma realidade determinada. Dessa maneira, ao promover a coexistência de defensores de diversas teorias, criou-se um ambiente propício para o desenvolvimento de uma abordagem nova, sem dogmatismo, tal qual afirma Di Filippo ao pontuar que

\footnotetext{
"El pensamiento económico y social latinoamericano se vio enriquecido por La Escuela Latinoamericana Del Desarrollo (ELD). Esta es la denominación con la que este ensayo engloba las contribuciones de distinguidos científicos sociales que $[\ldots]$ articularon sus ideasen torno a la visión centro-periferia formulada originalmente por la CEPAL. (DI FILIPPO, 2007, p.1)
}

Para desenvolvermos essa abordagem, a próxima seção aprofundará os pontos referentes à CEPAL, apresentando seus objetivos e histórico de constituição, até que, por fim, nos debruçaremos sobre as influências diretas de diversas correntes teóricas nessa formação.

\section{A COMISSÃO ECONÔMICA PARA AMÉRICA LATINA E O CARIBE (CEPAL)}

\section{Histórico de formação da $\mathrm{CEPAL}^{8}$}

\footnotetext{
${ }^{8}$ As atividades da CEPAL originalmente não abrangiam o Caribe. Posteriormente, esta região também foi incluída no escopo de suas preocupações, e em 1984 foi alterado oficialmente o nome da entidade, sem mudar o acrónimo nem em português, nem em espanhol.
} 


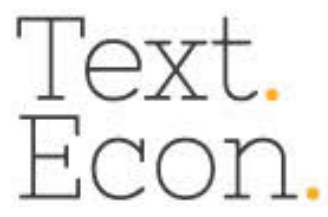

Nos setenta anos desde sua formação, a CEPAL deu grandes contribuições no que se refere ao desenvolvimento da região e, também, em termos de teoria econômica. Por isso ganhou reconhecimento mundial, tratando-se de uma referência imprescindível para todos aqueles que estudam a história econômica (e do pensamento econômico) da América Latina (BIELSCHOWSKY, 1998).

É importante pontuar que a CEPAL, enquanto instituição, construiu, por meio dos seus pesquisadores, uma teoria própria, cujo núcleo duro consiste em uma análise exclusiva para os problemas da América Latina e Caribe, com o propósito de se diferenciar das teorias do mainstream. O objetivo da CEPAL permaneceu intacto ao longo do tempo, todavia o escopo e os métodos das teorias desenvolvidas pela comissão foram sendo alterados, evoluindo para continuarem aderentes à realidade, acompanhando as mudanças inerentes ao processo de desenvolvimento da região e as mudanças gerais da situação socioeconômica no plano internacional.

Desde o início do processo de sua formação, a CEPAL buscou desenvolver uma metodologia própria, com o intuito de analisar a realidade da América Latina, considerando suas especificidades. Podemos considerar que esse objetivo foi alcançado e ainda hoje esse método, chamado "método histórico-estrutural", se mantém, ainda que com variações e atualizações que podem ser consideradas quase naturais (BIELSCHOWSKY, 2010). A noção geral do método é prover uma forma própria de refletir sobre como as instituições e a estrutura produtiva dos países já desenvolvidos economicamente influenciam na economia dos países em desenvolvimento, levando a resultados distintos dos observados nos estados-nação que já estão “consolidados” em sua dinâmica de produção e desenvolvimento econômico (ESTEVES, 2007).

O método pressupõe que, ao contrário do que sugerem muitas teorias econômicas, não é possível supor a existência de "estágios de desenvolvimento uniformes", como se para alcançar o desenvolvimento fosse necessário colocar-se em um caminho óbvio e contínuo, cujas diretrizes seriam as mesmas para os mais distintos países 9 (CARCANHOLO, 2005). O “desenvolvimento tardio ${ }^{10 "}$ dos países latino-

\footnotetext{
${ }^{9}$ O exemplo paradigmático dessa visão é Rostow (1964).

${ }^{10}$ Neste sentido, Colistete trata sobre as características do desenvolvimento tardio: "O 'capitalismo tardio' e seu modo de funcionamento são determinados por estruturas que caracterizam distintos períodos históricos. Nessa abordagem, as estruturas básicas são as forças produtivas e as relações de produção. Os demais elementos da economia (por exemplo, a ação do Estado, a inserção das empresas estrangeiras e as relações de trabalho) são derivados das características dessas estruturas em momentos específicos da história econômica brasileira - colonial, mercantil-escravista, exportadora-capitalista, industrialização restringida e industrialização pesada" (COLISTETE, 2001, p. 28).
} 


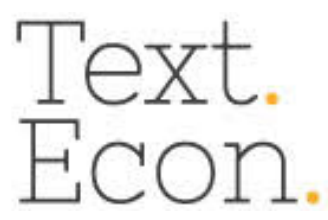

americanos e caribenhos demonstra, a partir de dados sobre essas realidades, que as dinâmicas são diferentes e que os países desenvolvidos estão posicionados em uma realidade muito diferente da que se vive na nossa região (COLISTETE, 2001). A partir dessa noção geral, os estudiosos vinculados à CEPAL desenvolveram termos como "relação centro-periferia" e "heterogeneidade estrutural", que serão mais explorados nas seções seguintes.

A CEPAL é uma das cinco comissões criadas pela Organização das Nações Unidas, divididas por região. O principal objetivo da criação da CEPAL, em 25 de fevereiro de 1948, foi o de promover avanços no desenvolvimento econômico dos países da América Latina, bem como aprimorar o relacionamento dos países, tanto dentro dessa região quanto com os demais países do mundo (CEPAL, 2018). Depois, entendeu-se que a Comissão deveria incorporar, também, questões relacionadas ao desenvolvimento social e aos países do Caribe. Além disso, através de uma atualização da missão da instituição, ficou decidido que se tornaria em um centro de excelência, com o objetivo de contribuir com análises do desenvolvimento dos países inseridos, lançando mão da formulação, acompanhamento e avaliação de políticas públicas focadas nas especificidades dos processos de desenvolvimento de cada país (BIELSCHOWSKY, 1998).

Definiu-se, também, que a CEPAL disponibilizaria a prestação de serviços especializados em áreas como o apoio à cooperação regional e internacional e o assessoramento aos governos, por exemplo. Entendia-se que o ideal de promover o desenvolvimento socioeconômico seria realizado por meio da cooperação e integração em escala regional, por meio de organizações e conferências intergovernamentais com especialistas em áreas específicas dos países inseridos e por meio do planejamento e execução de projetos de cooperação técnica, tanto no âmbito regional quanto em escala sub-regional (OCAMPO, 1998)

Após a análise da literatura pertinente (HAFFNER, 1996; BIELSCHOWSKY, 1998; RODRÍGUEZ, 2006; CEPAL, 2018), é possível identificar, em termos históricos, cinco grandes períodos nas contribuições da CEPAL ao longo de seus anos de existência:

1) Origem e primeiros desenvolvimentos, nos anos 1950: o objetivo central das contribuições cepalinas era o de argumentar em favor da industrialização na América 
Latina. Esta perspectiva propunha fomentar e consolidar a indústria como caminho ao desenvolvimento, dado que, até aquele tempo, as economias latino-americanas tinham seu foco na produção de bens primários para exportação, enquanto importavam bens acabados e tecnologicamente desenvolvidos (GONÇALVES, 2014). A proposta ficou conhecida como "industrialização por substituição de importações" e tem relação direta com o questionamento da lei das vantagens comparativas ${ }^{11}$.

O termo substituições de importações é conceituado por Coronel (2010, p.1) como "uma industrialização fechada, ou seja, ser voltada para dentro visando prioritariamente o mercado interno e dependente de políticas governamentais que protegessem a indústria nacional em relação aos seus concorrentes internacionais".

A substituição de importações como alternativa ao modelo primário-exportador que vigorava nos países da América Latina foi uma proposta defendida especialmente pelos economistas da CEPAL, tais como Aníbal Pinto, Celso Furtado, Raúl Prebisch e Maria da Conceição Tavares. A lógica desse processo é apresentada por Tavares:

A nossa tese central é de que a dinâmica do processo de desenvolvimento pela via de substituição de importações pode atribuir-se, em síntese, a uma série de respostas aos sucessivos desafios colocados pelo estrangulamento do setor externo, através dos quais a economia vai-se tornando quantitativamente menos dependente do exterior e mudando qualitativamente a natureza dessa dependência. Ao longo desse processo, do qual resulta uma série de modificações estruturais da economia, vão-se manifestando sucessivos aspectos da contradição básica que lhe é inerente entre as necessidades do crescimento e a barreira que representa a capacidade para importar (TAVARES, 2000, p.231).

Paradoxalmente, já no fim dessa década a CEPAL apontava alguns limites desse processo tal como tinha sido originalmente concebido: Um dos paradoxos do crescimento econômico da América Latina é que alguns
países que pretendiam diminuir sua vulnerabilidade através da industrialização
tornaram a se colocar numa situação muito vulnerável. Isso se deve,
justamente, ao fato de a política de substituição ter-se realizado em
compartimentos estanques. Nos países mais avançados da América Latina, a
substituição chegou a tais extremos que as importações ficaram reduzidas aos
produtos essenciais para manutenção da atividade econômica." (CEPAL
[1959], 2000, p. 363).

\footnotetext{
${ }^{11}$ Sobre a noção de vantagens comparativas e sua relação com o desenvolvimento dos países subdesenvolvidos, Nurkse (2010) [1953] afirma que: "A tese de que os países subdesenvolvidos deveriam progredir em direção ao seu 'crescimento equilibrado' e à 'diversificação' nem sempre é bem recebida. Não significaria isso um afastamento do princípio da vantagem comparativa? Por que esses países não atrelam suas exportações de produtos primários às regras de especialização internacional e importam os bens de que necessitam para uma dieta equilibrada?” (p.6). Após lembrar essa crítica, o próprio Nurkse (2010) [1953] apresenta os limites da perspectiva tradicional: "Impulsionar as exportações em face de uma demanda inelástica ou mais ou menos estacionária não seria um caminho muito promissor para o desenvolvimento" (p.6). Ao fim da reflexão proposta nesse momento do texto, há uma clara sugestão, por parte do autor, sobre a conveniência da ampliação do mercado interno.
} 
2) Anos 1960: dada a aceitação geral da perspectiva da substituição de importações, a produção intelectual da CEPAL nos anos 1960 voltou-se a pensar em maneiras de facilitar os processos de industrialização, dado que, apesar de que o objetivo estivesse bem definido, os desafios para alcançá-lo se sobressaiam frente às políticas adotadas pelos governos, dadas as características do contexto internacional.

Esta situação levava a um conflito com as previsões baseadas na teoria tradicional das Vantagens Comparativas. Com efeito, o crescimento do produto dos países periféricos não era acompanhado pelo ritmo de expansão de suas exportações. Isso ocorria devido a que os países periféricos tinham se especializado na produção de bens primários, cuja elasticidade-renda de demanda era baixa nos países centrais, em princípio os principais mercados para suas exportações. Manifesta-se assim a importância da restrição externa para a continuidade do processo:

$\mathrm{Na}$ superação contínua dessas contradições reside a essência da dinâmica do processo de substituição de importações. Teoricamente, o processo poderia continuar mediante uma seleção rigorosa do uso de divisas, até um ponto na divisão do trabalho com o exterior que correspondesse ao aproveitamento máximo dos recursos internos existentes (TAVARES, 2000, p.233).

Para que todo esse processo fosse bem-sucedido, era necessária a presença de uma certa atitude protecionista, o que também conflitava com a visão tradicional sobre o comércio internacional:

O processo de industrialização envolveria um "saudável" protecionismo, a defesa de uma política adequada de alocação dos recursos externos, a programação de substituição de importações, e cuidados para não diminuir ainda mais os salários, evitando a redução do nível de consumo das grandes massas tal que o planejamento do processo de industrialização pressupunha o fortalecimento das capacidades de regulação e decisão do Estado, o que implicava a adoção de mecanismos de controles cambiais, além da defesa da transferência dos centros de decisão para a periferia. (CARDOSO, 1995).

Nesses anos Prebisch, começou a sugerir que outros limites do processo de industrialização estavam sendo criados pelas estruturas sociais dos países latinoamericanos, especialmente pela estrutura agrária altamente concentrada; por esse motivo, nos anos 1960 ganharam destaque na CEPAL as propostas de reformas estruturas como condição necessária para viabilizar o crescimento econômico (RODRÍGUEZ, 2006) 


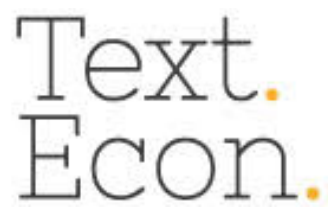

3) Anos 1970: nesse momento houve uma reflexão que se fazia necessária para entender os processos que estavam acontecendo na América Latina. As reformas pregadas não tinham se verificado, mas ainda assim alguns países estavam crescendo. Além disso, a presença de ditaduras em vários países da região, e inclusive no Chile, sede da CEPAL, levaram a uma crescente preocupação com os processos de desenvolvimento (BIELSCHOWSKY, 1998). Passou-se a destacar, na perspectiva de Aníbal Pinto, a existência de diferentes estilos de desenvolvimento. Em particular, destacou-se a necessidade de reorientar os "estilos" de desenvolvimento para promover a homogeneização social e a diversificação pró-exportadora, compreendendo a necessidade de diminuir as desigualdades sociais intrínsecas aos estados-nação menos desenvolvidos (ou, apenas: subdesenvolvidos) e as maneiras de repensar o desenvolvimento da periferia.

4) Anos 1980: as contribuições cepalinas àquele momento tiveram uma virada em relação à tradicional preocupação com o longo prazo. A inflação generalizada e a crise da dívida puseram um prêmio fundamental no curto prazo. As reflexões da CEPAL à época foram imprescindíveis, dado que apontavam na direção de um caminho para a superação do problema do endividamento externo, indicando a noção de "ajuste com crescimento", compatível com o momento histórico e com as especificidades regionais (BIELSCHOWSKY, 1998). A atitude da CEPAL nesses anos pode ser assim descrita:

O enfoque da CEPAL aos poucos passou a privilegiar o ajuste, debatendo suas ideias com as exigências dos órgãos multilaterais e a elas apresentando alternativas. Tanto que, em 1985, por pressão dos países em desenvolvimento, o governo norte-americano elabora o Plano Baker com o lema "ajuste com crescimento" sincronizando as políticas do FMI e do Banco Mundial que passam a associar a política do ajuste a uma estratégia de desenvolvimento. Em 1986, a CEPAL publicava um número do Cuadernos de la CEPAL com título sugerindo o mesmo esquema de ajuste associado ao crescimento: Crisis económica y políticas de ajuste, estabilización y crescimiento $\left(\mathrm{n}^{\circ}\right.$ 54, 1986). As preocupações dos documentos cepalinos deixaram de ser exclusivamente voltados para a política interna dos governos latino-americanos para incluírem no debate os organismos multilaterais e as agências de financiamento dos países centrais. (VITAGLIANO, 2004, p.170)

A noção de ajuste com crescimento estava inserida no mencionado contexto crise da dívida externa, problema enfrentado por diversos países da América Latina neste período. Neste sentido, de acordo com Haffner (2007), o momento era marcado por "Ajuste com crescimento; oposição aos choques do ajuste; necessidade de políticas 
de ingresso e eventual conveniência de choques estabilizadores; custo social do ajuste" e a saída que deveria ser seguida pelos países latino-americanos seria por meio da renegociação da dívida para ajustar o crescimento (BIELSCHOWSKY, 1998).

5) Anos 1990: em sintonia com sua contínua preocupação com os temas sociais, os estudos da CEPAL tiveram enfoque no que ficou conhecido como "transformação produtiva com equidade" ${ }^{12}$, do qual foi dito que "A proposta estratégica está articulada ao redor dos objetivos de cidadania - que se refere à equidade, à responsabilidade social, à transmissão de valores e à formação democrática" (OTTONE, 1993, p.14).

Neste sentido, entende-se que a questão de promover a "transformação produtiva com equidade" passou a ser a tarefa prioritária do desenvolvimento da América Latina e do Caribe durante os anos 1990 (ALMEIDA FILHO, 2003).

Fazendo um resumo da trajetória cepalina, começaríamos com as propostas de industrialização dos anos 1950; teríamos nos anos 1960 as reformas para desobstruir a industrialização; nos anos 1970, uma reorientação enfatizando os Estilos de Desenvolvimento; nos anos 1980, as preocupações para superar a crise da dívida; e culminando, nos anos 90, a preocupação com a Transformação Produtiva com Equidade (ALMEIDA FILHO, 2003).

Vale ressaltar que a CEPAL continua tendo muita importância atualmente, tanto por suas atividades internas como por seu relacionamento com diversos representantes governamentais. Os departamentos da agência mantêm algumas agendas com objetivos importantes, tais como a igualdade de gênero e o desenvolvimento sustentável. As atuais áreas de trabalho na CEPAL mostram que há mais preocupação com as questões

\footnotetext{
12 Esse é o nome do relatório publicado pela CEPAL em 1990. Segundo os autores, nesse documento a Secretaria da CEPAL fez um esforço para apresentar una versão decantada das principais lições que foram deixadas pela crise econômica dos anos oitenta (CEPAL, 1996). Almeida Filho (2003), p.3 explicita que "trata-se de um documento singular para a Agência, pelo seu foco parcial em questões macroeconômicas, embora em grande parte genérico nas suas proposições de políticas. O ponto de partida é a constatação do retrocesso experimentado pela grande maioria dos países em estudo, no âmbito econômico e social, em comparação aos sucessos de períodos anteriores, sobretudo do pós-guerra até a primeira crise do petróleo." E ainda: "No contexto em que veio a público, o documento "Transformação Produtiva' emblematizou uma importante mudança de rumos na concepção da CEPAL, uma vez que se tratava de um documento oficial, que contava, portanto, com a concordância dos países membros. O momento de divulgação dessas ideias coincide aproximadamente com a realização da conferência organizada pelo Instituto de Economia Internacional em 1989, em Washington, evento no qual um trabalho apresentado por John Williamson - Senior Fellow do mesmo instituto - acabou por cunhar a expressão 'Consenso de Washington', para expressar um conjunto de pontos de política econômica que deveriam ser adotados pelos países da América Latina e Caribe, na visão das instituições multilaterais sediadas naquela cidade." (Almeida Filho, 2003, p.5). Cabe ressaltar que as ideias do documento da eram bastante diferentes das propostas do Consenso de Washington.
} 


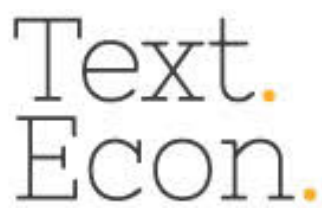

sociais do que se via no contexto de sua criação. Os atuais departamentos são: assuntos de gênero, comércio internacional e integração, desenvolvimento econômico, desenvolvimento produtivo e empresarial, desenvolvimento social, desenvolvimento sustentável e assentamentos humanos, estatísticas, planejamento para o desenvolvimento, população e desenvolvimento, recursos naturais e infraestrutura (CEPAL, 2018).

Esperamos ter deixado claro ao longo desta subseção que a CEPAL abarcou novos pontos de vista ao longo do tempo, incorporando-os em sua teoria para responder aos problemas de cada momento sem perder aderência à realidade. Todavia, assim o fez sem mudar seu núcleo duro, reafirmando a importância de pensar em métodos e teorias próprios para analisar as especificidades da realidade da América Latina e do Caribe.

\section{Teoria estruturalista e suas múltiplas influências}

Ao pensar a CEPAL como uma escola do pensamento econômico, deve-se notar que as teorias formuladas pelos expoentes do pensamento cepalino englobaram, em muitos momentos, argumentos e conceitos provenientes do pensamento keynesiano. Neste sentido pontua Fonseca (2000, p.334) que "não se pode desprezar a influência das ideias de Keynes sobre os principais expoentes da CEPAL, mas há que se ponderar que essa é apenas uma das vertentes teóricas que contribuíram para formar o chamado pensamento cepalino". Todavia, a CEPAL também recebeu outras contribuições que influenciaram direta e indiretamente em sua teoria.

Com base nisso, o objetivo desta seção é apresentar a influência de outras vertentes teóricas nas ideias da CEPAL, com o intuito de defender a interpretação desta perspectiva como fruto de uma atitude pluralista, para além da teoria keynesiana e da compreensão da Comissão como uma corrente heterodoxa.

Entende-se que a CEPAL pode ser considerada, desde sua constituição, como um centro heterodoxo, como sugerem Amado e Mollo (2004):

\footnotetext{
O pensamento sobre desenvolvimento econômico da CEPAL nasce de uma tentativa heterodoxa de compreensão do fenômeno do subdesenvolvimento, comum aos países latino-americanos, com base em uma interpretação que tinha por centro da análise as especificidades estruturais destes países. (AMADO e MOLLO, 2004, p.141)
} 


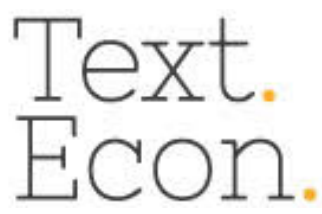

Esse vínculo com a heterodoxia estaria dado tanto pelo seu ponto de partida, que pretende analisar as especificidades da economia latino-americana, quanto por suas recomendações aos governos (AMADO E MOLLO, 2004). Entretanto, o intuito deste trabalho é mostrar a composição da teoria estruturalista (ou ideias cepalinas) enfatizando muito mais suas características pluralistas, foco das primeiras seções, para além do seu enfoque heterodoxo.

Enfatiza-se, todavia que, enquanto organização heterodoxa, a CEPAL pode (ou não) ser pluralista dentro das correntes heterodoxas ${ }^{13}$ ou, ainda, com alguns pontos que compreendem, inclusive, conceitos e abordagens ortodoxas, como se defende aqui, sendo pluralista em um sentido amplo do termo.

Amado e Mollo (2004, p.151) destacaram o caráter ortodoxo presente em várias teses cepalinas, especialmente nos estudos recentes, mas historicamente essas influências também podem ser registradas.

Um objetivo sempre mencionado pelos autores cepalinos é o de eliminar e a vulnerabilidade externa da região. Enfatiza-se também a luta contra a pobreza, articulando-a com a reforma agrária e com uma distribuição da renda mais justa. Para tanto, os autores criticam o padrão de consumo vigente, por seus reflexos sobre a poupança. Todavia, o destaque conferido à capacidade de poupar evidencia certas bases ortodoxas, interpretando que o investimento seria resultado da poupança gerada previamente. Este é o fundamento de que provedores de poupança são capazes de dinamizar a economia, ponto crucial na defesa dos padrões mais austeros. (FAJNZYLBER, 1990/CEPAL, 2000; BIELSCHOWSKY, 2000).

Não se deve negar as influências importantíssimas da teoria keynesiana - o que contribui, ainda, como já dito, para que a teoria estruturalista seja entendida como plural.

\begin{abstract}
Não há dúvidas de que, em largos traços, é possível associar pelo menos parte dos êxitos da difusão desde no pós-II Guerra à hegemonia do keynesianismo então verificada, com a expansão do Welfare State, das vitórias socialdemocratas e das políticas fiscais ativas voltadas para o pleno emprego nos principais países do Primeiro Mundo. Entretanto, esse ambiente mais amplo, pró-intervencionista e
\end{abstract}

\footnotetext{
${ }^{13}$ Não consideramos correto tratar a heterodoxia como uma única escola de pensamento. A ideia é pensar a heterodoxia considerando a diversidade inerente à mesma; ela seria, portanto, uma manifestação concreta dos ideais pluralistas. No caso da CEPAL, como um exemplo de 'muitas heterodoxias' - e também de um pouco de ortodoxia - entendemos que há pluralidade (como sinônimo de diversidade), e há, sobretudo, uma postura favorável para lidar com a diversidade (pluralismo, no sentido de postura ética).
} 
desenvolvimentista, é insuficiente para sustentar a relação entre Keynes e o pensamento cepalino de forma linear, até porque muitas das teses e termos teóricos consagrados mais tarde como "cepalinos", demonstrar-se-á, são encontrados no Brasil muito antes de a CEPAL ser criada e - o que é mais surpreendente - antes mesmo da publicação da Teoria Geral. (FONSECA, 2000, p. 334)

O enfoque estrutural da teoria cepalina teve como um dos principais expoentes se não o maior - Raúl Prebisch. As contribuições de Prebisch à CEPAL sempre destacaram a importância de se pensar em termos da perspectiva centro-periferia para avaliar de maneira global a economia mundial; ele enfatizava, além disso, a importância de construir a teoria de um ponto de partida focado na América Latina. Essa visão foi desenvolvida com uma linguagem própria de Prebisch e se cristalizou, em definitivo, em seu livro intitulado Capitalismo Periférico: crise e transformação (1981), em que ele incorpora plenamente a noção de capitalismo, relacionando-a com a posição periférica para embasar sua expressão "capitalismo periférico" e depois, o conceito de "centro-periferia".

Identifica-se curiosamente uma preocupação parecida no economista polonês Michal Kalecki quem, apesar de ser contemporâneo de Keynes e de ter recebido algumas influências deste, não pode ser considerado como um keynesiano no sentido mais estrito do termo. Kalecki, ao igual que Prebisch, destacava a especificidade das economias periféricas, ao afirmar que "El problema decisivo de las economias subdesarrolladas es distinto de aquél de los países desarrollados" (KALECKI, 1983, p.66).

Um fio condutor de todo o raciocínio de Prebisch é a noção de mudança tecnológica, vinculada ao desenvolvimento das forças produtivas; isto tem um embasamento teórico fortemente influenciado pelas análises feitas por Karl Marx e pelos conceitos inicialmente propostos por Schumpeter, embora focados em uma ótica direcionada à realidade latino-americana, que seria receptora passiva dessa mudança.

Ainda sobre as influências de Marx nas noções cepalinas, podemos encontrar outros elementos na visão de Celso Furtado, outra figura representativa da CEPAL. Bresser-Pereira afirma que:

Celso Furtado, interpretando livremente Marx, propôs que a ideia do desenvolvimento se constitui em dois momentos históricos e está intimamente relacionada com o processo de racionalização que caracterizará o mundo moderno. Em um primeiro momento, a racionalidade se revela pelo objetivo econômico definido com clareza 


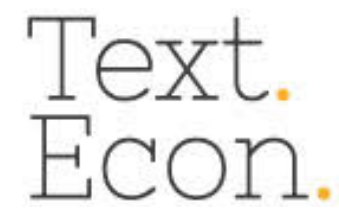

(o lucro), e pela adoção da acumulação de capital como meio de atingi-lo. (BRESSER-PEREIRA, 2006, p.4)

A mudança tecnológica, originada nos grandes centros, é apenas transferida às periferias, condição que caracteriza a América Latina. Essa transferência só ocorre à medida que for se tornando útil captar os recursos naturais provenientes desta região, conhecida por ser rica em recursos naturais e por ser exportadora de recursos primários (PAMPLONA e CACCIAMALI, 2017).

A capacidade de gerar progresso técnico é, na visão dos diversos expoentes do pensamento cepalino, o ponto crucial que confere vantagens aos grandes centros capitalistas das diversas épocas, tais como Estados Unidos da América e Inglaterra (DI FILIPPO, 2013). Essa noção está presente desde que a deterioração dos termos de intercâmbio foi pontuada, apontando, novamente, os limites da aplicação da visão das vantagens comparativas aos estados-nação subdesenvolvidos.

Ainda neste sentido, deve-se notar que os pioneiros da teoria do desenvolvimento analisaram este processo no contexto de um sistema internacional em que existem fortes assimetrias entre países, regiões e territórios quanto às capacidades tecnológicas (PREBISCH, 1949; HIRSCHMAN, 1958).

Explicam-se também as assimetrias entre o centro e a periferia pela maior capacidade de participação dos trabalhadores, por meio dos sindicatos das indústrias, nos países centrais; conseguem estes assim uma maior transferência do excedente termo originado na teoria desenvolvida pelos fisiocratas e incorporado pela teoria marxista - que decorre do progresso técnico aos seus salários, mantendo os preços altos das exportações. Isso combina com outro elemento importante que está contido nos escritos de Prebisch, a noção de poder entendida de forma multidimensional (poder econômico, poder sindical, poder político, social, etc.).

Ademais, quando as questões referentes ao progresso técnico são ponderadas como objetos centrais da análise, há que se destacar a influência de Schumpeter, outra das fontes das noções desenvolvidas pelos pensadores da CEPAL: "A mudança estrutural sempre esteve no centro da teoria do desenvolvimento. Esta visão se remonta, entre outros, a Schumpeter e sua ideia do desenvolvimento como um processo de destruição criativa" (PREBISCH, 1949; HIRSCHMAN, 1958).

Acrescenta-se, ainda, associando a visão schumpeteriana ao estruturalismo da CEPAL, a ideia de que os ajustes em uma economia - especialmente periférica, que é o 


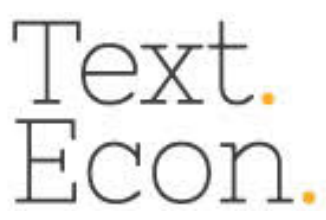

ponto central das análises cepalinas -, não se dão de forma automática, que não há uma tendência natural ao equilibro dos mercados e que, portanto, os ciclos econômicos são inerentes ao capitalismo, negando a noção mecânica que ronda a economia convencional:

A dinâmica das estruturas produtivas e ocupacionais próprias das economias centrais é incorporada à análise das tendências básicas do desenvolvimento das economias periféricas. Esse seria o sentido específico do caráter estrutural ao qual o subdesenvolvimento estaria associado. (SILVA e MARCATO, 2013, p.4)

Rodriguez (2006) afirma que um primeiro aspecto desse não-reducionismo, que se assemelha ao do Keynes, seria o destaque conferido ao papel do Estado; já um segundo aspecto, que se assemelha a Schumpeter, seria a negação de uma percepção mecanicista da esfera econômica.

A escola institucionalista pode ser também mencionada como uma das influências na construção teórica pluralista desenvolvida pela CEPAL. O reconhecimento dessa influência para a constituição da teoria cepalina está explicito inclusive no site da própria comissão:

Nos primeiros anos foi decisiva a influência do pensamento keynesiano e das escolas historicistas e institucionalistas centroeuropeias. Nos últimos anos, o foco tem sido a renovação do pensamento keynesiano, as novas teorias do comércio internacional e da organização industrial, as teorias evolutivas da firma e o novo institucionalismo (CEPAL, 2018)

É neste sentido que Aguilar Filho $(2009$, p.47) aponta ao dizer "A abordagem empregada pelos teóricos da CEPAL possui uma dimensão necessariamente histórica, com ênfase na análise da evolução institucional dos países latino-americanos e nos efeitos de suas contradições sociais."

Com isso, entende-se que é possível afirmar que o enfoque históricoestruturalista cepalino é derivado um método de produção científica profundamente atento para o comportamento dos agentes sociais e para a trajetória das instituições ao longo da história (BIELSCHOWSKY, 2000). Ao mesmo tempo em que ressalta a dimensão histórica dos fenômenos econômicos, o estruturalismo cepalino também dá ênfase às questões institucionais, observando a importância das preferências individuais e da cultura para a consolidação de sua condição periférica (AGUILAR FILHO, 2009, 


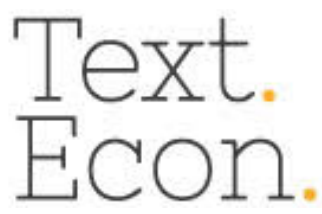

p.46-47). Podemos concluir, portanto, que o pensamento cepalino constitui uma escola de pensamento que adota uma abordagem pluralista.

\section{CONSIDERAÇÕES FINAIS}

Em face dos questionamentos pelos quais passou a ciência econômica a partir da crise financeira de 2008, e levando em conta as reflexões críticas trazidas no decorrer dos últimos anos por economistas, sociólogos e filósofos a respeito das limitações do fazer ciência em economia, este artigo buscou contribuir para esmiuçar as questões propostas pelos estudiosos do pluralismo das abordagens em economia.

Com a finalidade de colaborar para as discussões nas áreas de metodologia da economia e de história do pensamento econômico, inicialmente apresentamos o conceito de pluralismo e os seus desdobramentos teóricos referentes ao pluralismo das abordagens em economia; a seguir, buscamos verificar em que medida as teorias desenvolvidas pela CEPAL podem ser consideradas manifestações de uma atitude pluralista.

A noção de pluralismo das abordagens em economia sugere, em termos conclusivos, que a coexistência de múltiplas teorias para analisar uma realidade específica é benéfica para o desenvolvimento científico. Essa coexistência de múltiplas teorias é, então, contrária à noção de que é necessário que exista um paradigma dominante para que o conhecimento avance; da perspectiva pluralista decorre, portanto, uma postura ética, que promove o diálogo entre teorias distintas, para que seja possível utilizá-las quando melhor se aplicam à resolução de um problema em específico.

Entendemos que os desenvolvimentos teóricos cepalinos foram promovidos a partir dessa atitude; os economistas da CEPAL concretizaram, através de um método próprio, a noção de que muitas teorias podem fornecer inspiração e podem ser utilizadas - cada qual quando mais adequado -, para analisar os problemas de uma realidade específica, neste caso, a da América Latina e a do Caribe.

É importante pontuar que não é pretensão deste artigo minimizar a importantíssima influência keynesiana (e pós-keynesiana) na construção do arcabouço teórico cepalino. Entretanto, apontamos para as outras correntes teóricas que também impactaram na formação deste pensamento, como é o caso da teoria marxista, no tocante do processo de acumulação, ou da teoria institucionalista, quando se trata fala 


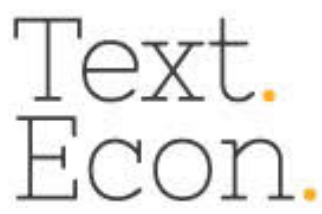

sobre a importância da cultura e das regras informais. Também destacamos a importância da perspectiva schumpeteriana quando se analisa o papel do empresário e as consequências da mudança tecnológica; destacamos também que a teoria kaleckiana encontra-se em sintonia com o objetivo da obra cepalina ao possibilitar um olhar diferenciado ao desenvolvimento dos países subdesenvolvidos, etc.

A argumentação final deste estudo é que a multiplicidade de teorias convivendo no mesmo espaço e tempo é muito vantajosa para uma análise mais completa da realidade, lançando luz sobre múltiplos problemas econômicos, de maneira a apreender melhor a complexidade inerente à economia, objetivo em grande medida alcançado pela CEPAL.

\section{REFERÊNCIAS BIBLIOGRÁFICAS}

AGUILAR FILHO, H. A. O institucionalismo de Douglass North e as interpretações weberianas do atraso brasileiro. Tese de Doutorado em Economia, PPGE/UFRGS, 2009.

AHUMADA, J.M. e DI FILIPPO, A. "Economía Política Global". In D. Bello e E. Valenzuela (eds.), Manual de Ciência Política. Santiago: RIL Editores, 2013.

ALMEIDA FILHO, N. "O Desenvolvimento da América Latina na Perspectiva da CEPAL dos anos 90: correção de rumos ou mudança de concepção?”. In: J.C. FERRAZ, M. CROCCO e L.A. ELIAS (Orgs.), Liberalização Econômica e Desenvolvimento: modelos, politicas e restrições. São Paulo: Futura, 2003.

AMADO, A. M. e MOLLO, M. L. "Ortodoxia e Heterodoxia na discussão sobre Integração Regional: A Origem do Pensamento da CEPAL e seus Desenvolvimentos Posteriores". Estudos Econômicos, 34 (1), 2004.

BIANCHI, A. M. "Muitos métodos é o método: a respeito do pluralismo". Revista de Economia Política. 12 (2) [46)], 1992.

BIELSCHOWSKY, R. "Evolución de las Ideas de la CEPAL". Revista de la CEPAL, Número Extraordinario [Octubre], 1998.

BIELSCHOWSKY, R. (org.). Cinqüenta anos de pensamento da CEPAL. Rio de Janeiro: Record, 2000.

BIELSCHOWSKY, R. "Maria da Conceição Tavares". Revista de Economia Contemporânea, 14 (1), 2010.

BRESSER-PEREIRA, L. C. "O Conceito Histórico de Desenvolvimento Econômico". Textos para Discussão FGV/EESP, 157, 2006 (Disponível em: http://bresserpereira.org.br/o-conceito-historico-de-desenvolvimento-economico-2/, acesso em 20/12/2017).

CALDWELL, B. Beyond Positivism: Economic Methodology in the Twentieth Century. London: George Allen \& Unwin, 1982. 
CARCANHOLO, M. D. "Dependência e Superexploração da Força de Trabalho no Desenvolvimento Periférico". In: Seminário Internacional REG GEN: Alternativas à Globalização, $2005 \quad$ (Disponível em http://bibliotecavirtual.clacso.org.ar/ar/libros/reggen/pp06.pdf, acesso em 20/12/2017).

CARDOSO, F. H. "Desenvolvimento: o mais político dos temas". Revista de Economia Política, 15 (4), 1995.

CASANOVA, P. G. As Novas Ciências e as Humanidades: da Academia à Política. São Paulo: Boitempo, 2006.

CEPAL. Significación del mercado común en el desarrollo económico de América Latina. El Mercado Comun Latino Americano, E/CN 12/531, Santiago do Chile: Nações Unidas, Texto Redigido por Raul Prebish, CEPAL, Op. cit., [1959], 2000.

CEPAL. Transformación Productiva con Equidad. Santiago: CEPAL, 1990.

CEPAL. Página oficial de la CEPAL. Disponível em https://www.cepal.org/pt-br Acessada em 20/02/2018.

COLANDER, D. "The death of Neoclassical economics". Journal of the History of Economic Thought, 22, 2000.

COLISTETE, R. P. “O desenvolvimentismo cepalino: problemas teóricos e influências no Brasil”. Estudos Avançados, 15 (41), 2001.

CORONEL, D. A: Resenha de 'O processo de substituição de importações'. Revista de Economia Política, vol. 30, no 2 (118), p. 357-358, 2010.

DEQUECH, D. "Neoclassical, mainstream, orthodox, and heterodox economics". Journal of Post Keynesian Economics, 30 (2), 2007.

DI FILIPPO, A. "La Escuela Latinoamericana del Desarrollo: Tensiones epistemológicas de un movimiento fundacional”. Cinta Moebio, 29, 2007.

DI FILLIPO, A. "Poder, Capitalismo y Democracia". Revista Encrucijada Americana, 6 (1), 2013.

DOW, S. "Structured Pluralism”. Journal of Economic Methodology, 11 (3), 2004.

ESTEVES, T. J. Modelos de desenvolvimento e integração latino-americanos: da CEPAL ao Consenso de Washington. Dissertação de Mestrado em Ciências Sociais Aplicadas/ UFRRJ, 2007.

FERNÁNDEZ, R.G. A metodologia como argumento a favor de uma economia pluralista. In: J. GUILHOTO, P. G. DUARTE \& S. SILBER (Orgs.), O Brasil e a ciência econômica em debate - Volume 2 - $O$ estado da arte em economia. São Paulo: Saraiva, 2011.

FEYERABEND, Paul K. Contra o método. Rio de Janeiro: Francisco Alves, 1977.

FONSECA, P. C. D. “As Origens e as Vertentes formadoras do pensamento cepalino". Revista Brasileira de Economia, 54 (3), 2000.

FURTADO, C. Formação econômica do Brasil. São Paulo: Nacional, 24. ed., 1991.

FURTADO, C. O mito do desenvolvimento econômico. São Paulo: Paz e Terra. 1996. 
FURTADO, C. Introdução ao Desenvolvimento: Enfoque Histórico-Estrutural. São Paulo: Paz e Terra, 2000.

GONÇALVES, R. S. "A CEPAL dos anos 50 e sua influência no pensamento político brasileiro". Pensamento Plural, 15 (2), 2014.

GOUlART, M., VASCONCELOS, D. S., FERNANDEZ, R. G. "Mais Pluralismo: considerações sobre a relevância do manifesto por uma economia pós-autista". Anais do XXI Encontro Nacional de Economia Política, São Bernardo do Campo, 2016.

HAFFNER, J. CEPAL: uma perspectiva de desenvolvimento latino-americano. Porto Alegre: EDIPUCRS, 1996.

HIRSCHMAN, A. O. The strategy of economic development. New Haven (CT): Yale University Press, 1958.

KALECKI, M. Crescimento e Ciclo das Economias Capitalistas. São Paulo: HUCITEC, 1983.

KEYNES, J. N. The scope and Method of Political Economy. Kitchener (Canada): Batoche Books, 1999 [1891].

LEIJONHUFVUD, A. "Life among the Econ”. Western Economic Journal, 11(3), 1973.

MARIN, S. R. “A análise situacional de Karl Popper: alguma analogia com a lógica da situação na economia?”. Economia e Sociedade, 17 (2), 2008.

NURKSE, R. "Alguns Aspectos Internacionais do Desenvolvimento Econômico". In A.N. AGARWALA \& S.P. SINGH, Eds., A Economia do Subdesenvolvimento. RJ: Contraponto, 2010.

OCAMPO, J. "Cincuenta Años de la CEPAL". Revista de la CEPAL, Número Extraordinario [Octubre], 1998.

OTTONE, E. Educação e Conhecimento: Eixo da Transformação Produtiva com Equidade (uma visão sintética). Brasília: MEC/INEP, 1993.

PAMPLONA, J. B. e CACCIAMALI, M. C. "O paradoxo da abundância: recursos naturais e desenvolvimento na América Latina". Estudos Avançados, 31 (1), 2017.

PIERCE, C. S. Collected Papers of Charles Sanders Pierce. Cambridge, MA: Harvard University Press, 1935.

POPPER, K. A Lógica da Pesquisa Científica. São Paulo: Cultrix 1974 [1934].

PREBISCH, R. Capitalismo periférico: crisis y trasformación. México DF: Fondo de Cultura Económica, 1987.

PREBISCH, R. El desarrollo económico de América Latina y algunos de sus principales problemas. In R. BIELSCHOWSKY (org.), Cincuenta Años de Pensamiento en la CEPAL: Textos Seleccionados. Santiago: Fondo de Cultura Económica-CEPAL, 1998.

RODRÍGUEZ, Octavio. El estructuralismo latinoamericano. México DF: Siglo XXI/CEPAL, 2006.

ROSTOW, W. W. Etapas do desenvolvimento econômico: um manifesto nãocomunista. Rio de Janeiro: Zahar, 1964. 
SANTOS, J. F. Realismo e Falibilismo: um contraponto entre Pierce e Popper. Tese de Doutorado em Filosofia/PUC-SP, 2006.

SCARANO, E. R. Los debates teóricos en economía: el pluralismo de Sheila Dow. Trabalho apresentado no XL Congresso da Asociación Argentina de Economía Política, 2005.

(Disponível em http://www.aaep.org.ar/espa/anales/works05/scarano.pdf).

SCHORN R., FALKENBACH, E. M. F. "Falibilismo: crítica e coerência linguística". Thaumazein, 3 (5), 2010.

SILVA, A. L. G e MARCATO, M. B Estruturalismo Latino-Americano e Desenvolvimento na perspectiva Neo-Schumpeteriana. Trabalho apresentado na Conferência Internacional LALICS, 2013. (Disponível em: http://www.redesist.ie.ufrj.br/lalics/papers/124Estruturalismo LatinoAmericano e Desenvolvimento na Perspectiva NeoSchumpeteriana.pdf. Acesso em 20/09/2016).

VITAGLIANO, L. F. A CEPAL no fim do milênio: a resposta aos programas de ajuste neoliberais. Dissertação de Mestrado em Ciência Política/UNICAMP, 2004. 